مدى توافر معايير الجودة الشاملة بِ برنامج التربية العملية 2ِ كلية التربية بجامعة إب

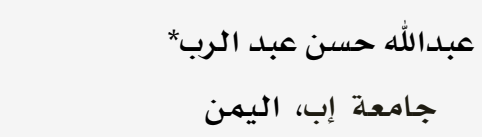

قبل بتاريخ:

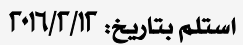

ملخص: هدفت الدراسة إلى التعرف على مدى توافر معايير الجودة الشاملة ِِّْ برنامج التربية العملية ِِّ2كلية التربية بجامعة إب من

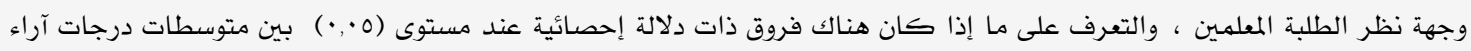

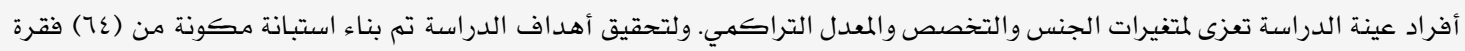

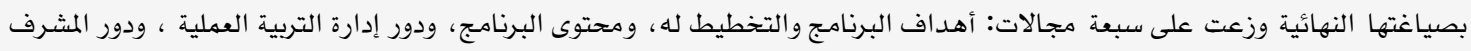

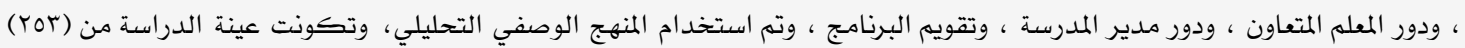

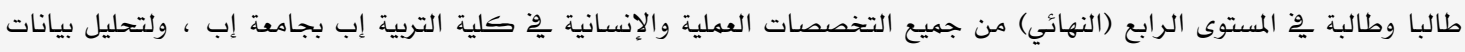

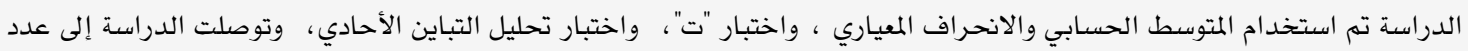

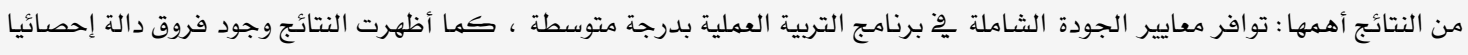

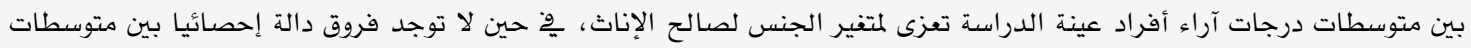

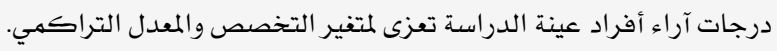

\title{
The Extent of Availability of the Total Quality Standards in the Practicum Program in the College of Education at Ibb University
}

Abdullah H. Abdulrab*

Ibb University, Yeman

\begin{abstract}
The study aimed to identify the extent of availability of the total quality standards in the practicum program in the College of Education at Ibb 'niversity from the viewpoint of teacher students. It also aimed to examine the differences among teacher students attributed to the variables of gender, specialization and overall average. A questionnaire of 64 items was prepared and distributed on seven domains: the objectives and planning of the program, content of the program, the role of practicum administration, the role of monitoring, the role of cooperating teacher. the role of school manager, and evaluation of the program. The sample of the study consisted of 253 final year students. The mean scores, standard deviation, " $t$ " test and one way ANOVA were used. The results of the study revealed that the degree of availability of the total quality standards of the practicum program was medium. However, the findings indicated that there were significant differences between male and female participants in favor of females, in addition, there were no significant differences among teacher students attributed to the variables of specialization and overall average.
\end{abstract}

Keywords: Total quality standards, practicum program, teacher students.

*dr.abduhotllah2013@yahoo.com 
الأطراف دورا مهما بِّ إنجاح البرنامج وتحقيق أهدافه، لذا لابد من كل طرف أن يدرك مسؤولياته ليؤدي دوره على أكمل وجه ، ومن هذه الأطراف ما يأتي: أولا إدارة التربية العملية التابعة لقسم المناهج وطرائق

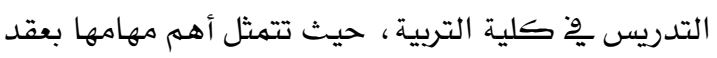
الندوات للطلبة المعلمين قبل البدء بالتطبيق الميداني لتبصير الطلبة المعلمين بطبيعة العمل، وتزويد كل طالب بدليل تبين حقوقه وواجباته هِّ المدرسة المتعاونة،

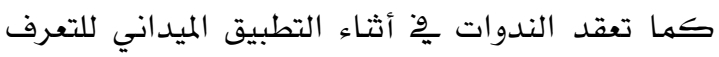

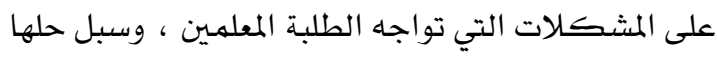

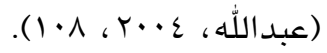

ثانيا المشرف وهو أحد أساتذة كلية التربية الذي يتولى مهمة الإشراف على الطالب المعلم أثاء فترة التطبيق الميداني قِّ المدرسة المتعاونة، ويقوم بتقديم العون

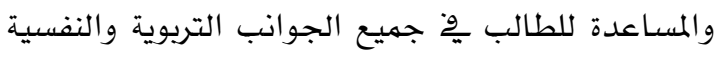

$$
\text { والتخصصية (عامر، 1+r، •V). }
$$

ثالثا المعلم المتعاون وهو المعلم الذي يقوم بتدريس مادة تخصصه بِّ المدرسة المتعاونة ، وتكمن أهميته بِّ أنه

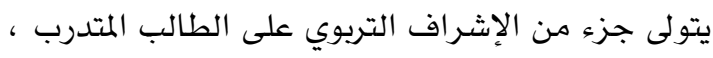

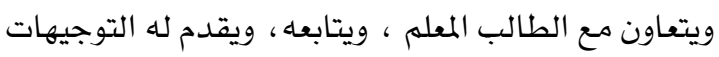

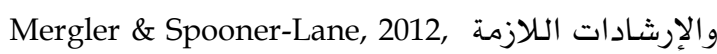

رابعا مدير المدرسة وهو الشخص المسئول عن إدارة مدرسة التطبيق ويقدم العون والمساعدة للطلبة المعلمين، ويعد عنصرا أساسيا بِّ برنامج التربية العملية لما له من لهن دور فاعل يٌْ دعم الطلبة المعلمين، ورعايتهم، وتطوير

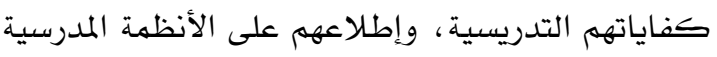

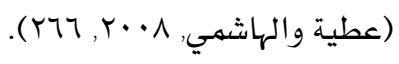

خامسا الطالب المعلم الذي يعد المستهدف بِّ برنامج التربية العملية، ومحورها الرئيس، وعلى بقية الأطراف

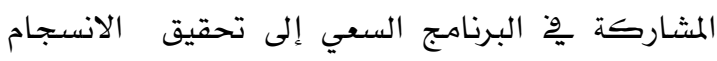
للطالب المعلم مع البيئة المدرسية لتحقيق الهدف الأساسي المئي

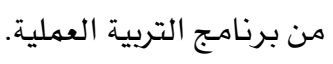

ومن أجل تحقيق جودة التعليم بِّ مؤسسات إعداد

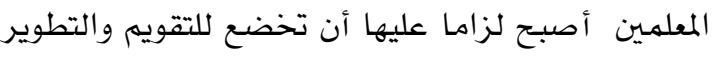

يشهد عالمنا المعاصر عددا من التغيرات بِّ شتى الميادين، لذا بات من الضروري أن تواكب هذه التغيرات تطورات

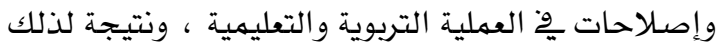

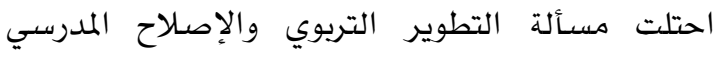

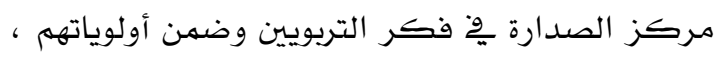

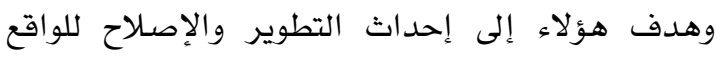
التعليهي ِّْ جوانبه المتعددة لتحقيق النجاح التلازم التتشئة

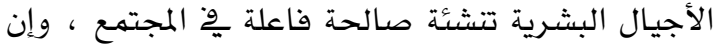
السعي إلى تحقيق هذا النجاح يتطلب توفير معلمين

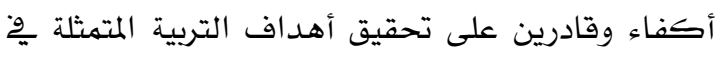
إعداد النشء إعدادا شاملا متكاملا. وتعد عملية إعداد المعلم الكفء وتأهيله من أولويات مؤسسات إعداد المعلم، وذلك انطلاقا من مبدأ أن إن المنات المعلم هو أساس العملية التربوية والتعليمية وعليه يتوقف

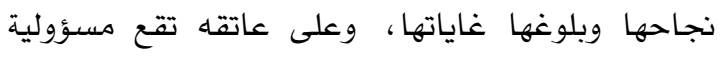
تربية النشء الصالح الذي يعمل عل بناء المجتمع ، وهذا ولنها

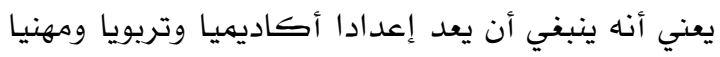
وثقافيا واجتهاعيا حتى يتمكن من القيام بدوره المهني

بنجاح. لذا يعد برنامج التربية العملية أو الميدانية من أهم برامج إعداد المعلمين قبل الخدمة ، فالتربية العملية تمثل هن اهن العمود الفقري لبرامج إعداد المعلم بِّ الكليات

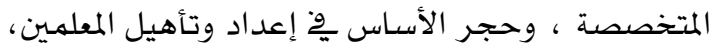
ومن دونها لا يمكن للجوانب الأكاديمية والتربوية

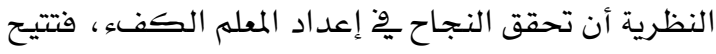

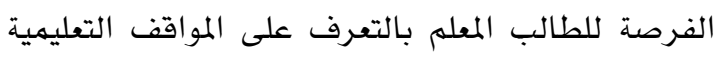

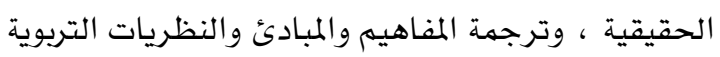

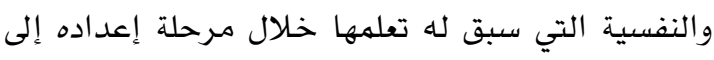

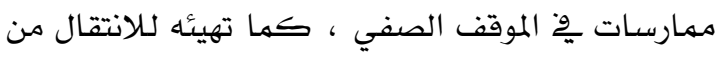
دور الطالب إلى دور المعلم ، وتخلق لديه الاتجاهات

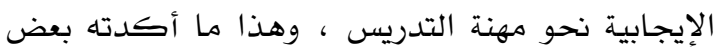

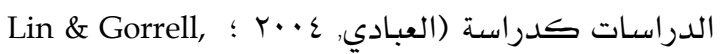
1998 وتعد الأطراف والعناصر المشاركة ِِّ برنامج التربية العملية عناصر أساسية وتكاملية تعمل على نجاح أو الوناه فثل التربية العملية ، حيث يؤدي كل طرف من هذه 
وعدم تلبية مخرجات الجامعات لحاجات سوق العهل، وازدياد المنافسة بين الجامعات، لذا تعد معايير الجودة

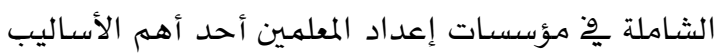

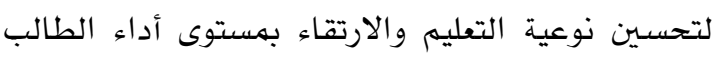

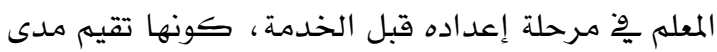
مطابقة مخرجات المؤسسة لمعايير الجودة الشـاملة. فارتبطت حركة المعايير ارتباطا وثيقا بحركتين

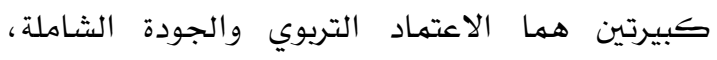
وشكلت الحركات الثلاث فكرا تربويا ثلاثي الأبعاد ، لذلك تهثل المعايير المدخل الحقيقي لتحقيق جودة التعليم

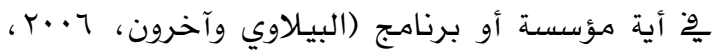

وبـالنظر إلى واقـع برنـامج التربيـة العمليـة على المسـتوى العـالمي والإقليمسي والمحلـي نجـده يواجـه تحـديات متعـددة

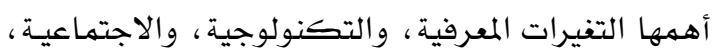
والاقتصـادية ، والسياسـية ، والـتي أدت إلى تفـير صـورة العـالم بأكملـه، مهـا اسـتوجب على مؤسسـات التعليم العالي وجميع أنظمتها التربوية والتعليميـة تطوير برنـامه

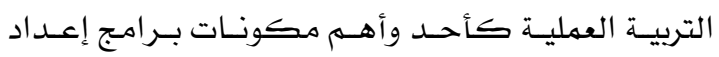

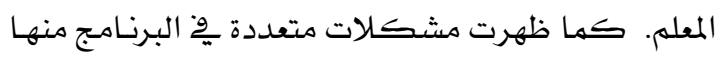

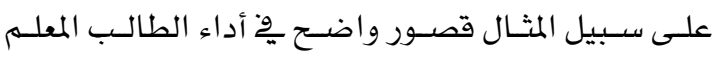
للجانب التدريسي، وأن برنامج التربية العمليـة يعاني مـن سوء الإشراف، ونشوء الصراع بين الطالب المعلى والمعلى

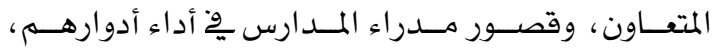
وشعور الطالب المعلم بعدم القبول والتقدير مـن قبـل إدارة المدرسـة أثناء فترة التطبيق الميـداني، وقلـة الفـترة الزهنيـة المحـددة لبرنـامج التربيـة العمليـة ، وهـــا مـا أشـارت إليـه

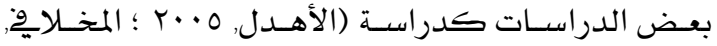

؛ Rahph et al., 2007 ! Seferoglue, 2006 ؛ • •

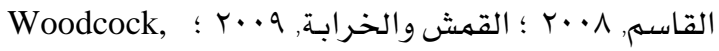

.(Akarsu \& Kaya, 2012 2011

يتضـح مها سبق بأن الجودة الشاملة أصبحت اتجاهـا عالميا لتجويد التعليم، إلا أنتا نجد مها لا شك فيه أن كلية التربية بجامعة إب مازالت تقتقر لمعايير الجودة الشاملة، ومن أجل تحقيق جودة برناهج التربية العملية يْ كلية التربية بجامعة إب، التي تتعكس على تميز المخرجات التعليمية المتمثلة پو
بشكل مستهر بحيث يكفل قدرتها على مواجهة تحديات العصر ومواكبة جميع التطورات المتسارعة، وِوْ أواخر القرن العشرين اقترح بعض التربويين مدخلا

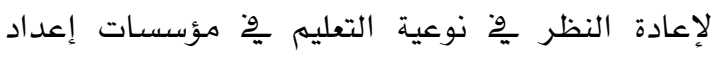
المعلمـين يْ عدد من دول العالم عن طريق إدخال منظومة

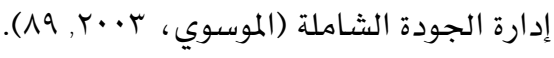
ونظرا لأن مواكبة مؤسسات إعداد المعلميـن لمتطلبات الجودة يعد أمرا حيويا لنهضتها وتقدمها وكسب ثقة

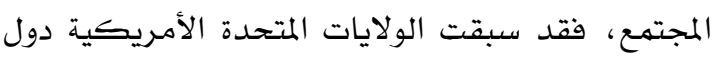
العالم بحْ تبني نماذج عالمية لتوكيد الجودة لمؤسسات إعداد المعلمـين، فقامت بتأسيس مجالس غير حكومية مثل مجلس اعتماد التعليم العالي الأمريكي (CHEA) ، The Council for Higher Education Accreditation ومن أشهر تلك المعايير معايير المجلس الوطني الأمريكي لاعتماد إعداد المعلهـين وِّ أمريكا (NCATE)، والمعايير المهنية للمتخرجين وفقا لاتحاد وتقييم المعلمـين الجدد بِ

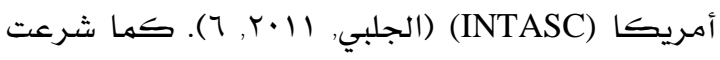
الدول العربية بإقامة المؤتهرات والندوات والدراسـات وورش العهل الهادفة إلى إرساء ثقافة الجودة والاعتماد وِّ المؤسسات والبراهج على مستوى الأقطار. فهدف المؤتهر الثاني عشر لوزراء التعليه العالي والبحث العلمي ِّخ الوطن العربي الذي عقد تحت شعار "المواءهة بين

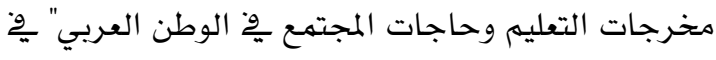
بيروت 9 +rام ، إلى تجسيد وتلبية أهداف ومخرجات مؤسسات التعليم العالي المتطلبات وحاجات المجتمـع وسوق العمل (المنظمة العربية للتربية والثقافة والعلوم، 9 • · ، r). وعلى المستوى المحلي ازداد الاهتمام بقضية

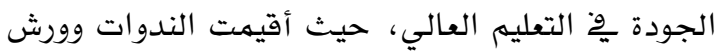
العمل، منها ندوة "التتمية المهنية مدخلا لتحقيق الجودة مِّ التعليم الجامعي" والتي عقدت بِ جامعة صنعاء

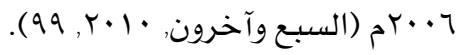
فالاهتهام بهعايير الجودة ِِّ مؤسسات التعليم العالي عالميا وإقليميا ومحليا لا يعد ترفا تتطلع إليه المؤسسـات التعليمية ، ولم يأت بالصدفة أو رغبة يخٌ تقليد الآخرين بل أصبح ضرورة ملحة تمليها حركة التغيير المعاصرة

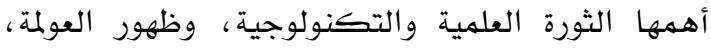


ما درجة توافر معايير الجودة الشاملة پِّ برنامج التربية العملية جِّ كلية التربية بجامعة إب من وجهة نظر الطلبة المعلمين؟

هل توجد فروق ذات دلالة إحصائية عند مستوى (0.,•) بين متوسطات درجات آراء أفراد عينة الدراسة هِّ مدى إحساتية

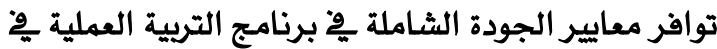
كلية التربية بجامعة إب تعزى لمتفيرات الجنس والتخصص والمعدل التراكميء أهداف الدراسة تسعى الدراسة لتحقيق الأهداف الآتية: 1. الوقوف على معايير الجودة الشاملة التي يمكن بِّ ضوئها تقويم برنامج التربية العملية وِّ كلية التربية بجامعة إب. Y. التعرف على مدى توافر معايير الجودة الثاملة وِّ برنامج التربية العملية ِِّ كلية التربية بجامعة إب. r. التعرف على ما إذا كان هناك فروق ذات دلالة إحصائية عند مستوى (0•,•) بين متوسطات درجات آراء أفراد عينة الدراسة تعزى لمتغيرات الجنس والتخصص والمعدل التراكمي.

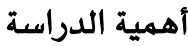
تتجلى أهمية الدراسة الحالية بِّ الآتي: تعد استجابة للاتجاهات العالمية المعاصرة الني

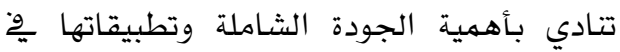

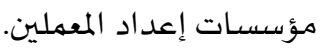
تسهم الدراسة بِّ توفير قائمة بهعايير الجودة الشاملة اللازمة لتقويم برنامج التربية العملية. تفيد نتائج الدراسة المعنيين بتطوير برنامج

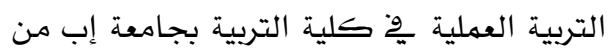
خلال الإسهام بها ستقدماه من نتائج وتوصيات. تفيد بِّ تشخيص جوانب القوة وجوانب الضعف وِّْ برنامج التربية العملية، ومن ثم تعزيز جوانب القوة، ومعالجة الجوانب السلبية بغرض تطوير

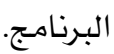

تحقيق أهداف التربية العملية، فإنه لابد من إخضاعها للتقويم پِّ ضوء معايير الجودة الشاملة ِِّ ظل توجهات إدارة الجامعة لتطبيق نظام الجودة الشاملة ِِّ الجامعة بهدف تطويره وتلبية احتياجات المجتمع من المعلمين ذوي الكفاءة والقادرين على تحقيق الأهداف التربوية المنشودة ، لذلك وجد المدات الباحث حاجة لإجراء الدراسة والكشف عن مدى توافر معايير الجودة الشاملة بِّ برنامج التربية العملية بِّ كلية التربية بجامعة إب من وجهة نظر الطلبة المعلمين كونهم

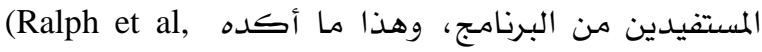
2007, 2) على ضرورة الاهتهام وعدم تجاهل آراء ووجهات نظر الطلبة المعلمين عند تقويم برنامج التربية العملية. مشكلة الدراسة

من خلال عمل الباحث ِِّ الفترة السابقة كعضو هيئة

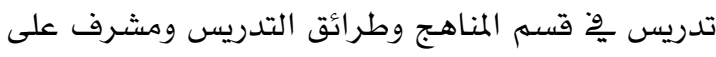
الطلبة المعلمين جِّ المدارس، وحديثا كرئيس لقسم

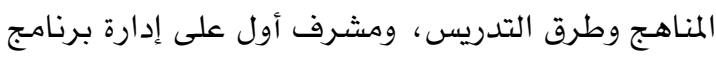

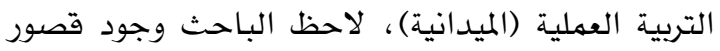

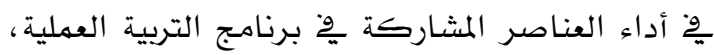
وكذلك قلة الفترة الزمنية التي يقضيها الطالب المعلم وِّ2

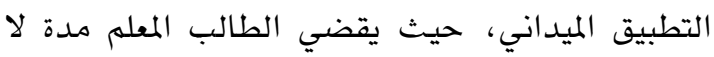

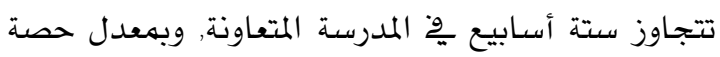
واحدة بِّ الأسبوع، وبالتالي تعد هذه الفترة قصيرة جدا

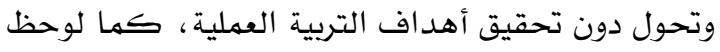
شكاوى كثير من مدراء المدارس حول قصور أداء

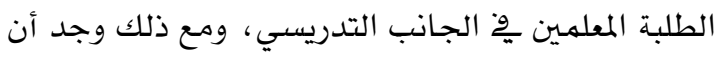
الدرجات التي يحصل عليها الطلبة المعلمين بعد الانتهاء من فترة التطبيق الميداني متضخمة حيث تصل نسبة الذين يحصلون على تقدير ممتاز (10٪) تقريبا. مها سبق تبلورت مشكلة البحث، التي عززت إحساس الباحث بها بأن برنامج التربية العملية بحاجة ماسة إلى

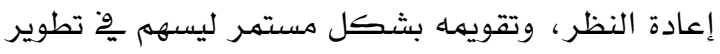
وتحسين البرنامج بما يحقق الجودة الثاملة. لذا تحاول الدراسة الحالية الإجابة عن التساؤلات الآتية: 
والشروط إلى مخرجات تتصف بالجودة، وتعمل على تلبية احتياجات المستفيدين من هذا البرنامج، ويقاس

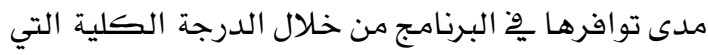
يتم الحصول عليها من استجابات أفراد عينة الدراسة

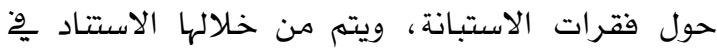
إصدار الحكم على برنامج التربية العملية.

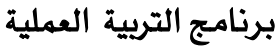

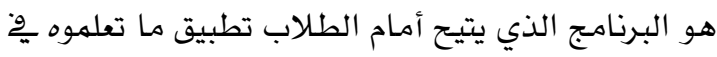

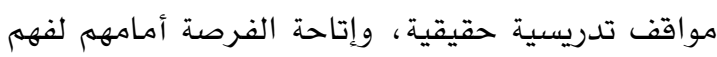
النطاق الكامل لدور المعلمين من خلال التدريس الفعلي وذلك تحت إثراف مشرف متخصص (201i \& File, و

ويعرف برنامج التربية العملية وِّ هذه الدراسة بأنه برنامج تدريبي من برامج إعداد المعلم قبل الخدمة ،

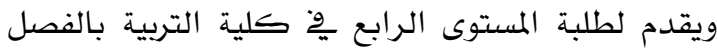
الدراسي الأول، حيث يقوم الطلبة المعلمون بتدريس

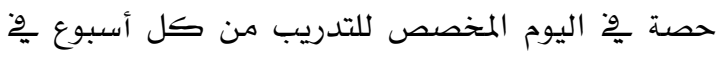
إحدى المدارس المتعاونة تحت إثراف أعضاء من هيئة التدريس، ومن ثم تقويم الطلبة المعلمين بعد الانتهاء من التطبيق الميداني.

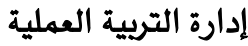

وتعرف إدارة التربية العملية ِّْ هذه الدراسة بأنها إدارة تتبع قسم المناهج وطرائق التدريس هِّ كلية التربية بجامعة إب، وتتولى مهمة تخطيط وتتفيذ وتقويم برنامج

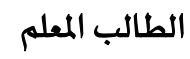

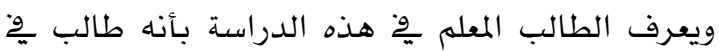

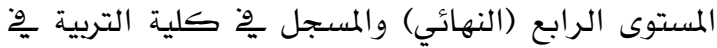
أحد التخصصات الإنسانية أو العلمية، ويقوم بالتطبيق

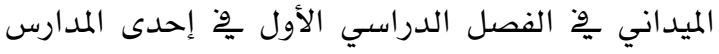

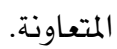

ويعرف المشرف بِّ هذه الدراسة بأنه عضو هيئة التدريس ٌِ كلية التربية بجامعة إب، الذي تسند إليه

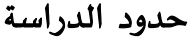
تقتصر الدراسة الحالية على الحدود الآتية: الحدود الموضوعية: وتتهثل بِّ مدى توافر معايير الجودة

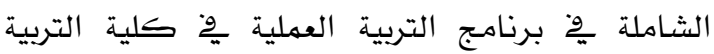
بجامعة إب. الحدود البشرية: جميع طلبة المستوى الرابع (تخصص:

علوم قرآن، لغة عربية، رياضيات، فيزياء، كيمياء). الحدود المكانية: كلية التربية بجامعة إب. الحدود الزمنية: أجريت الدراسة بِّ الفصل الأول للعام

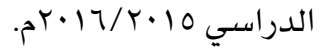

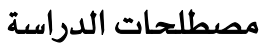

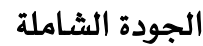
يعرفها عشيبة بأنها "مجمل المعايير والخصائص التي ينبغي أن تتوافر بِّ جميع عناصر العملية التعليمية بالجامعة - سواء منها ما يتعلق - بالمدخلات أو العمليات

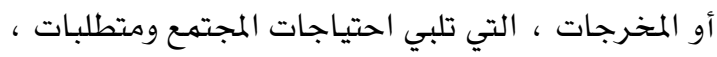
ورغبات المتعلمين وحاجاتهم ، وتتحقق من خلال الاستخدام الفعال لجميع العناصر البشرية والمادية

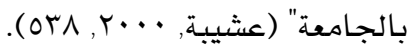

معايير الجودة الشاملة

تعرف بأنها "الحصول على منتج جيد من خلال تحسين

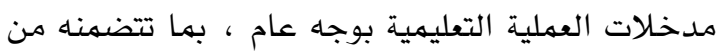
طالب ، وإدارة مؤسسية ، ومباني ، ومرافق ، وتحسين العيان أداء المعلم وأداء الطالب وأداء المؤسسة ، وإجراءات ومرجعيات العملية التعليمية بها يسهر وِّ تحسين مخرجات العملية التعليمية ومن أهمها متخرج الجامعة لهاهي

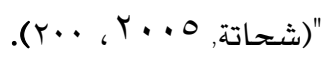

وتعرف إجرائيا بأنها مجموعة من المواصفات والشروط التي ينبغي توافرها بِّْ برنامج التربية العملية (التطبيق

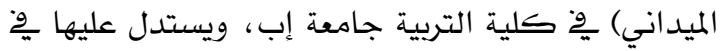
جودة جوانب البرنامج الذي يشمل أهداف البرنامج والتخطيط له، ومحتوى البرنامج، ودور إدارة التربية

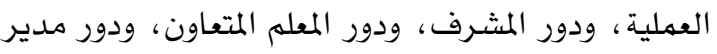

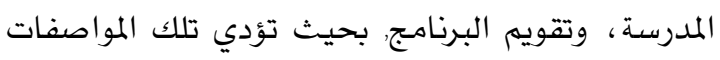


جدول 1

\begin{tabular}{|c|c|c|c|}
\hline \multicolumn{4}{|c|}{ توزيع أفراد العينة وفقا لمتغيرات الدراسة } \\
\hline النسبة & العدد & المتغير & \\
\hline \multicolumn{4}{|c|}{ 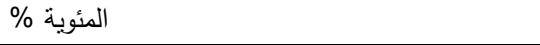 } \\
\hline$r 9,0$ & $1 \ldots$ & ذكور & \\
\hline 7,0 & lor & إناث & \\
\hline$\varepsilon 9, \varepsilon$ & ro & إنساني & \\
\hline $0,, 4$ & iru & علمي & \\
\hline iv & $\varepsilon r$ & جيد جدا & \\
\hline & & فاعلى & المعدل \\
\hline 00 & 149 & جيد & 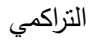 \\
\hline ru & $v_{1}$ & مقبول & \\
\hline$\% 1 .$. & ror & مجموع & \\
\hline
\end{tabular}

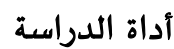

ههمة الإشراف على الطلبة المعلمين ِِّ المدارس المتعاونة

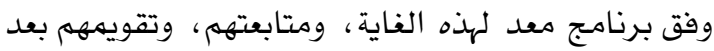
الانتهاء من التطبيق الميداني.

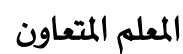

ويعرف ِّْ هذه الدراسة بأنه المعلم الأساسي والمقيم بِّ المدرسة المتعاونة التي يتدرب فيها الطالب المعلم.

$$
\text { مدير المدرسة }
$$

ويعرف مدير المدرسة بِّ هذه الدراسة بأنه الشخص المسئول عن إدارة المدرسة المتعاونة وِّو الحلقة الأخيرة (9- V) من مرحلة التعليم الأساسي أو المرحلة الثانوية $(1 \mathrm{r}-1 \cdot)$

\section{منهجية الدراسة وإجراءاتها}

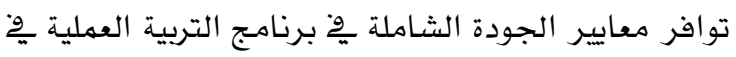

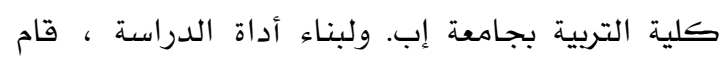

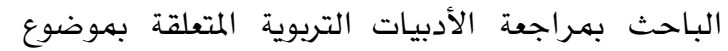
الدراسة إضافة إلى الخبرة العلمية فِّ مجال التربية العملية. وتكونت الاستبانة من جزأين :الأول معلومات

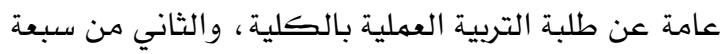
مجالات وهي :المجال الأول (أهداف البرنامج والتخطيط له) ويتضمن (1) فقرات، والمجال الثاني (محتوى الثال

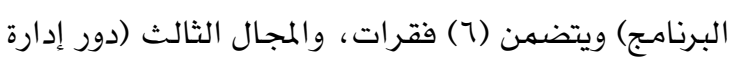

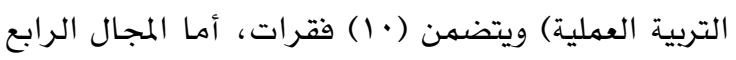

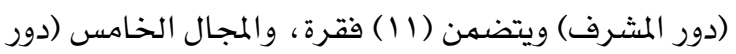
المعلم المتعاون) ويتضمن (11) فقرة، وِّ حين المجال السادس (دور مدير المدرسة) يتضمن (·ل) فقرات،

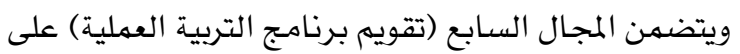

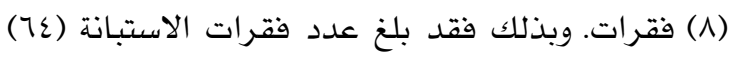

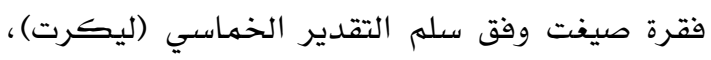

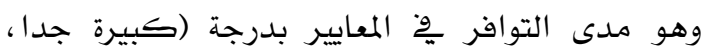
كبيرة، متوسطة، قليلة، قليلة جدا).

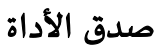
اعتمدت الدراسة ِِّ التحقق من صدق الاستبانة على صدق المحكهين، وذلك من خلال آراء المحكهين،

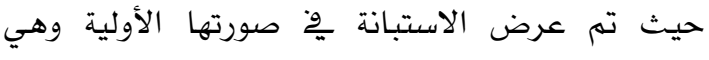
مكونة من (V) فقرة على عدد من أعضاء هيئة

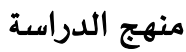

اعتمدت الدراسة المنهج الوصفي التحليلي، لملاءمة

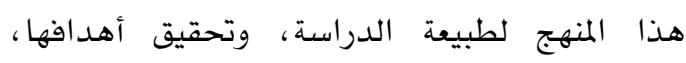
والوصول إلى إجابات تسهم بِّهُ وصف وتحليل نتائج استجابات طلبة كلية التربية بجامعة إب حول برنامج

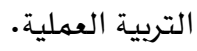

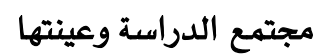

يتكون مجتمع الدراسة من جميع طلبة المستوى الرابع

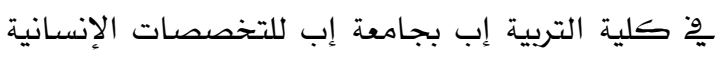
(علوم قرآن، لغة عربية)، والتخصصات العلمية (رياضيات، فيزياء، كيمياء)، الملتحقين بيرنامج التربية

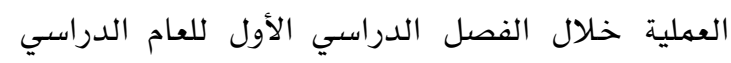

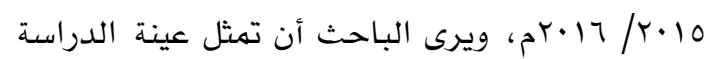

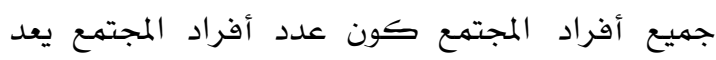
المكتملة، أصبح عدد أفراد العينة مكونا من (Yor)

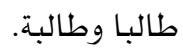
والجدول الآتي يبين توزيع أفراد عينة الدراسة تبعا

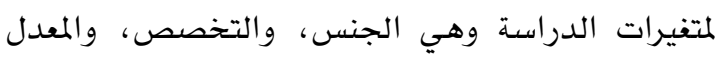

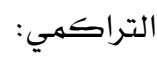

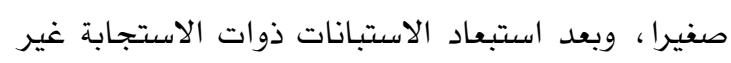


للإجابة عن هذا السؤال، تم استخراج المتوسطات الحسابية والانحرافات المعيارية لاستجابات أفراد العينة

على مجالات الاستبانة السبعة ، كما يوضحه جدول r :

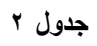

المتوسطات الحسابية والانحرافات المعيارية لكل مجال من مجالات الاستبانة

\begin{tabular}{|c|c|c|c|c|c|}
\hline \multicolumn{6}{|c|}{ السبعة } \\
\hline التوافر & الترتيب & المعباري & الحسنوسط الحسبي & المجال & م \\
\hline متوسطة & 1 & $\cdot, \leq 4$ & $r, r q$ & 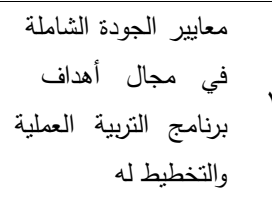 & 1 \\
\hline متوسطة & 7 & $\cdot, 01$ & r,Ao & 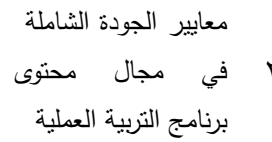 & r \\
\hline متوسطة & v & $\cdot, \leqslant V$ & $r, v q$ & في معايير الجودة الثاملة & r \\
\hline متوسطة & $r$ & $\cdot, V r$ & $r, r$. & في مجال دور المشرف الثشاملة & $\varepsilon$ \\
\hline متوسطة & 。 & $\cdot, 0$. & $r, 90$ & 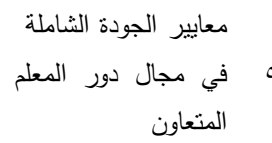 & 。 \\
\hline متوسطة & $\varepsilon$ & •, TV & $r, 11$ & ـ معي مجال دور مدير الجودة الثاملة & 7 \\
\hline متوسطة & r & $\cdot, \leqslant V$ & r, & 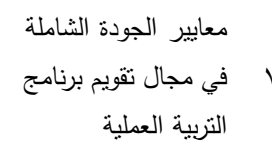 & v \\
\hline متوسطة & & • & $r, 11$ & لأداة مجموع معايير مجالات & \\
\hline
\end{tabular}

يتضح من جدول ץ أن المجال الأول حصل على الترتيب

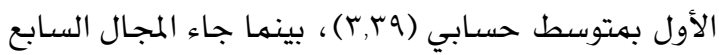
على الترتيب الثاني بمتوسط حسابي (T,Y,)، وجاء

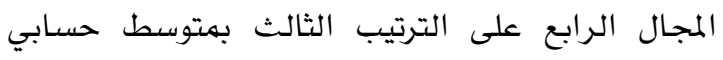
(r,r.r.r)، وِّ حين جاء المجال السادس على الترتيب الرابع

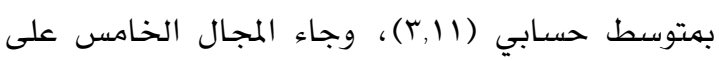
الترتيب الخامس بهتوسط حسابي (Y,90), وحصل المجال الثاني على الترتيب السادس بهتوسط حسابي

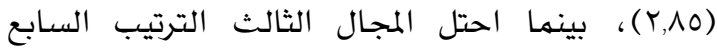
بمتوسط حسابي (Y,V9).
التدريس المتخصصين، وذلك للتأكد من وضوح

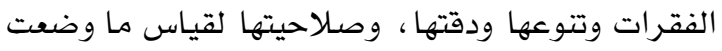

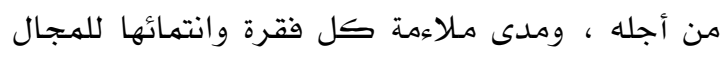

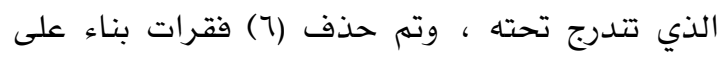

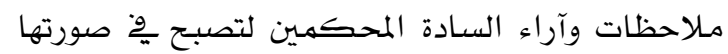
النهائية مكونة من (ع7) فقرة ، كما تم التأكد من صدق الاستبانة إحصائيا باستخدام صدق الاتساق

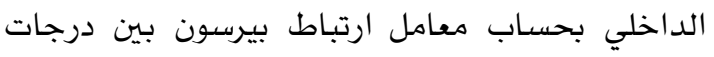

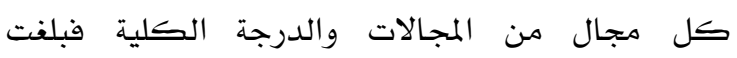

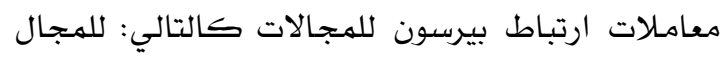
الأول (rی,·•)، وللمجال الثاني (•^,•)، وللهجال الثالث

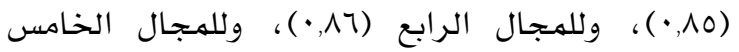

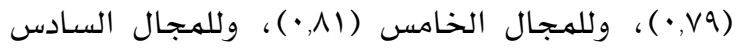

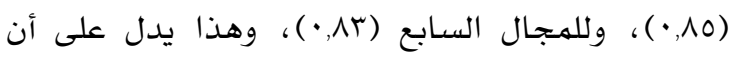

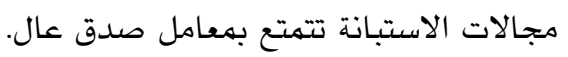

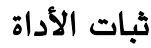
تم التأكد من الثبات من خلال حساب معامل ألفا

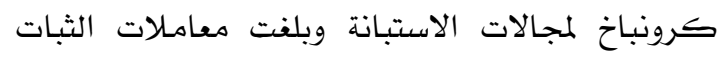

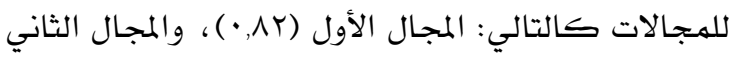

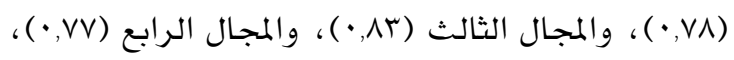
والمجال الخامس (عی,•)، والمجال السادس (r/, •)، والمجال السابع (1, •)، وتعد هذه القيم عالية ومقبولة.

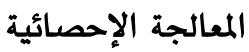
استعان الباحث بالرزمة الإحصائية للعلوم الاجتماعية

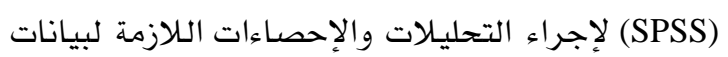
الاستبانة ، حيث تم استخدام المتوسط الحسابي،

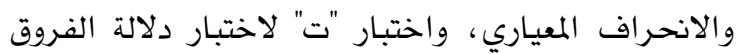
بين متوسطات استجابات أفراد عينة الدراسة تعزى لمتغيري الجنس والتخصص، واختبار تحليل التباين الأحادي لاختبار دلالة الفروق بين متوسطات استجابات أفراد عينة الدراسة تعزى لمتفير المعدل التراكمي. أولا: النتائج المتعلقة بالإجابة عن السؤال الأول ما درجة توافر معايير الجودة الشاملة بِّ برنامج التربية العملية فِ كلية التربية بجامعة إب من وجهة نظر الطلبة المعلمينs 


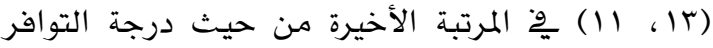
بدرجة متوسطة للفقرة (II))، وبدرجة قليلة للفقرة (1). ويعود السبب يخ ذلك إلى ضعف الإمكانات المادية ِّ. توفير التقنيات التعليمية ِّْ برنامج إعداد المعلم، الأمر

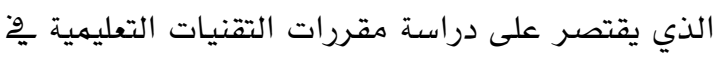
برنامج إعداد المعلم بشكل نظري، ويحول دون اكتساب الطالب المعلم لمهارات استخدام التقنيات التعليمية، كما أن طرائق التدريس المتبعة ِِّ البرنامج

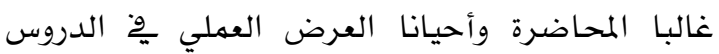
العملية فقط، هع إغفال كل الطرائق والأسـاليب الحديثة ِِ التدريس ، وقد يرجع ذلك لتدريس طرق التدريس بشكل نظري يخلو من الممارسة والتطبيق. ويلاحظ من مرفق ا بأن المتوسط الحسابي لدرجة توافر معايير الجودة الشـاملة ِّْ برنامج التربية العملية

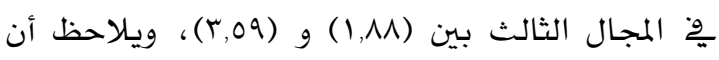

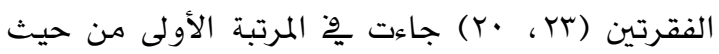
درجة التوافر بدرجة كبيرة للفقرة (YM)، وبدرجة

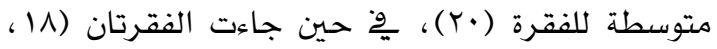
(IV قليلة. ويعزو الباحث ذلك إلى أن إدارة التربية العهلية مازالت حديثة التأسيس ولا تملك الميزانية الكافية للقيام بههامها ، كها أن الفترة الزمنية القصيرة للتطبيق الميداني لا تسهـح بإجراء لقاءات مع رؤسـاء الأقسـام والطلبة المعلميني، وتم تفسير سبب قلة الفترة الزمنية مسبقا ، كما أن توزيع الطلبة على المدارس لا يتم وفق التخصصات المختلفة أو حسب ظروف إمكانات

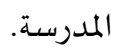

كما يتضسح من مرفق ا بأن المتوسط الحسابي لدرجة توافر معايير الجودة الثـاملة ِّْ برنامج التربية العملية

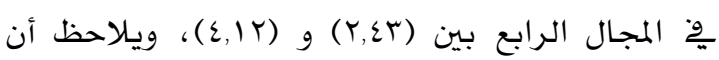

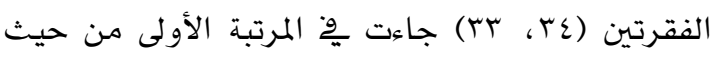
درجة التوافر بدرجة كبيرة، وِّ حين جاءت الفقرتان

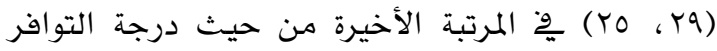
بدرجة متوسطة للفقرة (Yq) وبدرجة قليلة للفقرة (Y0). ويعزى ذلك إلى أن إدارة التربية العملية تستعين بنسبة

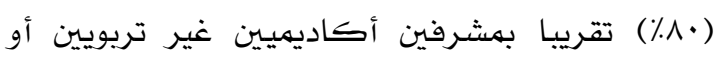

وهذا يدل على أن معايير جودة برنامج التربية العملية وِّ مجملها جاءت بدرجة توافر متوسطة، مها يعني أن البرنامج بحاجة إلى مزيد من الاهتمام من كلية التربية بجامعة إب.

ويوضح مرفق ا المتوسطات والانحرافات المعيارية لاستجابات أفراد العينة على فقرات مجالات الدراسة السبعة، وتم ترتيب الإجابات بحسب المتوسط الحسابي.

يتضح من مرفق ا بأن المتوسط الحسابي لدرجة توافر

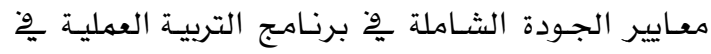

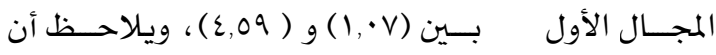
الفقـرتين (r, 0) جـاءت بِّ المرتبـة الأولى مـن حيـث درجـة

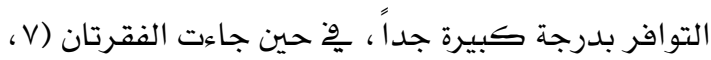

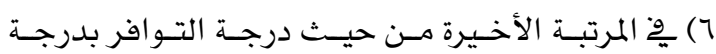

متوسـة للفقـرة (V) ، وبدرجـة قليلة جـداً للفقـرة (7). ويعزو الباحث ذلك إلى أنه توجد أهداف محـددة لبرنـاهـج التربيـة العمليـة إلا أن بعض الطلبـة المعلمـين ليسـوا على

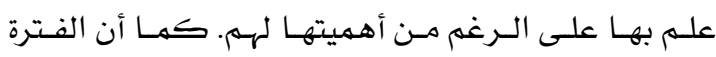

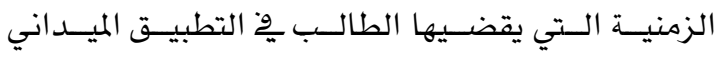
(الممارسـة المنفصـلة) لا تتجــاوز سـتة أسـابيع أي إجهـالي

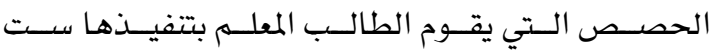
حصـص، وهــا بسـبب عـدم التوافتق الـزمني يخّ ابتـداء العام الدراسـي للهـدارس وابتـداء العـام الدراسـي لكليـة التربيـة ، إضـافة إلى تـأخر نتـائج طلبـة المسـتوى الثالـث

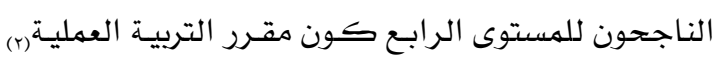

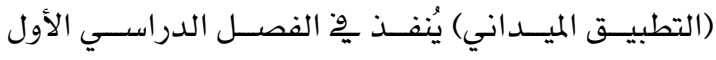

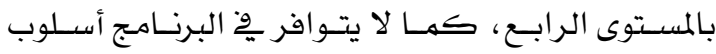

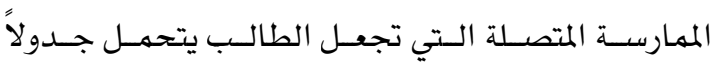
كامـلاً ولا يهارس الطالب المعله التدريس طوال الأسبوع لمبول

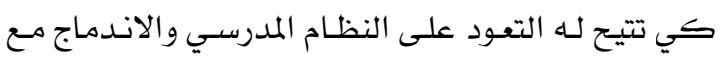

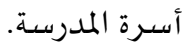

كما يبين مرفق ا بأن المتوسط الحسابي لدرجة توافر معايير الجودة الشاملة پِّ برنامج التربية العملية وِية

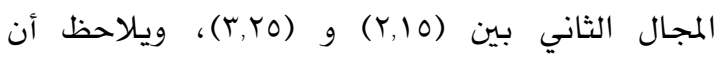

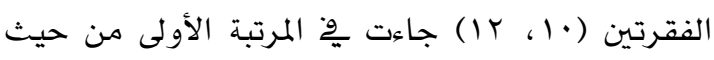
درجة التوافر بدرجة متوسطة، ِِّ حين جاءت الفقرتان 
المنفصلة بوْ برنامج التربية العهلية التي تقوم على تدريس الطالب المعلم ليوم واحد بالأسبوع بِّ المدرسة المتعاونة تجعل مدراء المدارس ينظرون للطالب المعلم نظرة الطالب المتدرب وليس كمعلم متدرب، على العكس إذا ما طبق أسلوب الممارسة المتصلة ِِّ برنامج التربية العملية التي تساعد الطالب المعلم على التكيف مع البيئة المدرسية ، وتجعل مدير المدرسة يتعامل مع الطالب المعلم

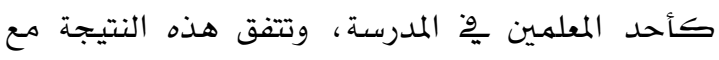

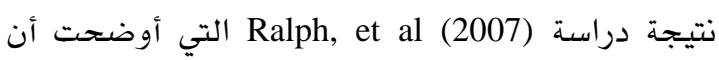

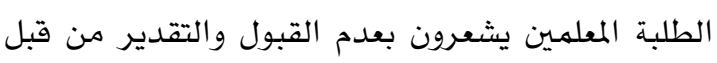

مدير المدرسة، وكذلك مع نتيجة دراسة الغيشان والعبادي (r/.r) التي أظهرت أن ممارسات مدراء المدارس بْ برنامج التربية العملية جاءت بدرجة متوسطة، فضلا عن نتيجة دراسة الشهراني (•l. (r) التي كشفت أن معايير الجودة الشاملة بِّ مجال مدير المدرسة كانت متحققة إلى حد ما. وأخيرا يظهر مرفق ا بأن المتوسط الحسابي لدرجة

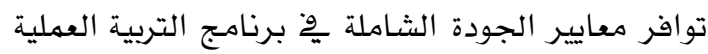

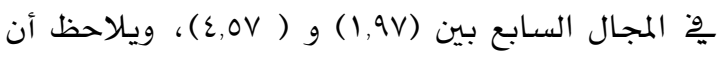

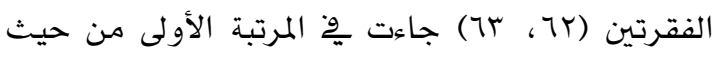
درجة التوافر بدرجة كبيرة جدا، پِّ حين جاءت الفقرتان (09، ع7) وِّ المرتبة الأخيرة من حيث درجة التوافر بدرجة قليلة. ويعود ذلك إلى اقتصار تقويم

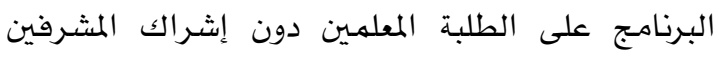

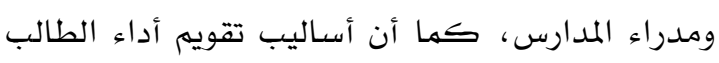
المعلم تقتصر على المشرف غير التربوي أو غير المؤهل

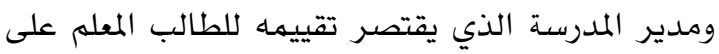
الحضور خلال فترة التطبيق الميداني، وعدم إشراك

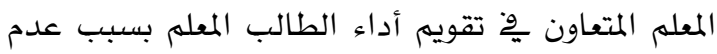

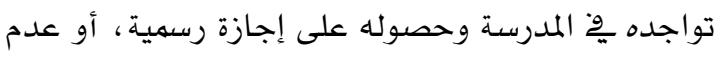

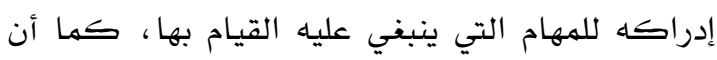

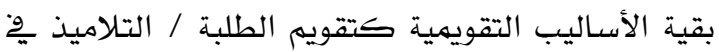
المدرسة المتعاونة، واستخدام ملف الإنجاز يتطلبان وقتا وجهدا كبيرين، وفترة زمنية طويلة للتطبيق الميداني لا

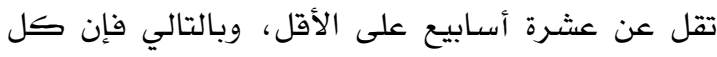
العوامل السابقة أدت إلى تضخم درجات الطلبة المعلمين
معيدين للإشراف على الطلبة المعلمين، وذلك بسبب أن

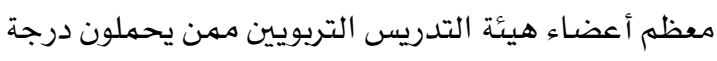

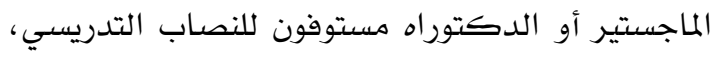

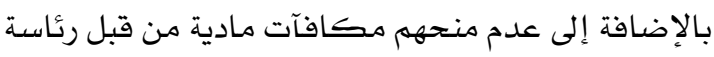
الجامعة، وبالتالي فإن المشرف الأكاديهي الغير تربوي أو المعيد لا يمتلك خبرة كافية فيما يتعلق بتخطيط وتتفيذ وتقويم الدرس ، وتتفق هذه النتيجة مع نتيجة

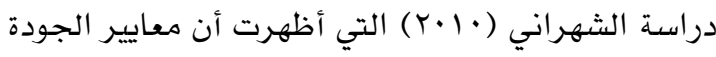
الشاملة بِّ مجال المشرف كانت متحققة إلى حد ما. وأيضا يبين مرفق 1 بأن المتوسط الحسابي لدرجة توافر معايير الجودة الشاملة وِّ برنامج التربية العملية

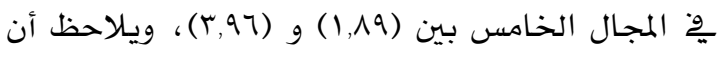

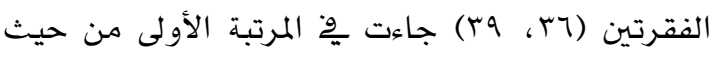

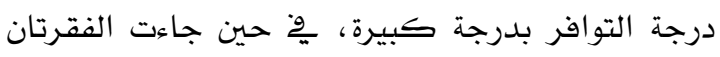

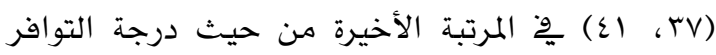
بدرجة قليلة. ويعود السبب وِّ ذلك إلى أن المعلم المتعاون يقتصر دوره على تحديد الوحدات الدراسية للطالب

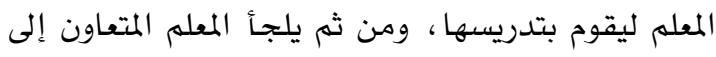
الحصول على إجازة رسمية من مدير المدرسة بحجة

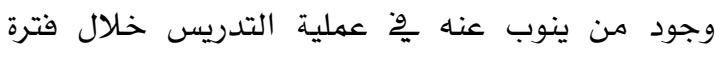

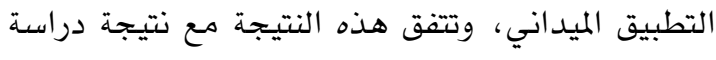
Ralph, et al (2007) التي أشارت إلى أن الطلبة المعلمين يعانون من وجود الصراع مع المعلم المتعاون، وكذلك إلك المان

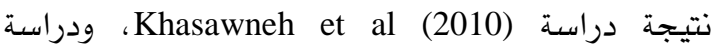
Akarsu \& Kaya (2012)

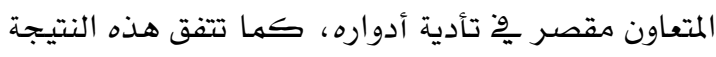

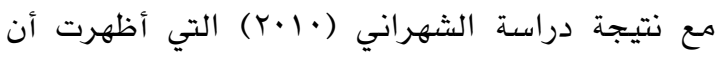
معايير الجودة الشاملة ِِّْ مجال المعلم المتعاون كانت متحققة إلى حد مـا.

ويلاحظ أيضا من مرفق ا بأن المتوسط الحسابي لدرجة توافر معايير الجودة الثـاملة ِِّ برنامج التربية

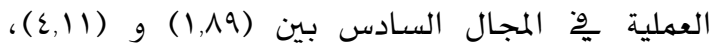

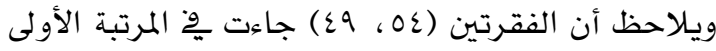
من حيث درجة التوافر بدرجة كبيرة، پِّ حين جاءت

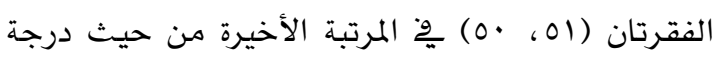

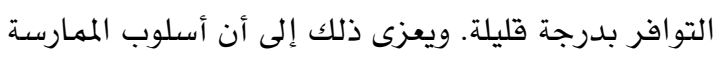


من (0., ·)، كما أن قيمة "ت" للأداة ككل بلفت

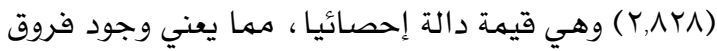
دالة إحصائيا عند مستوى (0•, •) بين استجابات أفراد عينة الدراسة حول تقديرهم لمدى توافر معايير الجودة الشاملة پِّ برنامج التربية العملية ِِّ كلية التربية بجامعة إب تعزى لمتفير الجنس لصالح الإناث، واختلفت

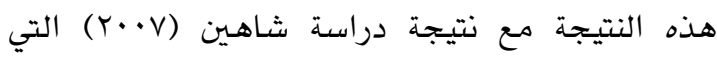
أظهرت عدم وجود فروق ذات دلالة إحصائية بين متوسطات تقديرات الطلبة المعلمـين على برنامج التربية

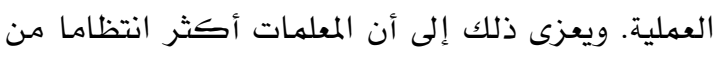

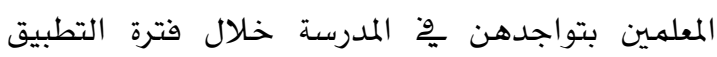
الميداني، وأكثر حرصا على تقديم العون والمسـاعدة للطالبات المعلمات، كها أن مديرات المدارس أكثر إدراكا من مدراء المدارس بالدور المناط عليهن تجاه الطلبة المعلمين ِِّ تعريف الطالبات المعلمات باللوائح والأنظمة المدرسية ، ومتابعة حضورهن وتواجدهن خلال اليوم الدراسي، وتشتجيعهن بالمثاركة ببعض الأنثطة

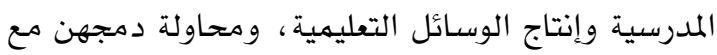
معلمات المدرسة، كما أن مديرات المدارس أكثر

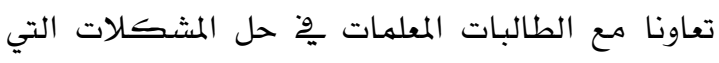
تواجههن خلال فترة التطبيق الميداني.
وِّ مقرر التربية العمليةر (التطبيق الميداني). وتتقق هذه

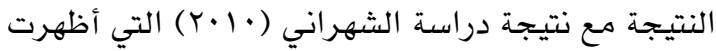
أن معايير الجودة الشاملة ِِّ مجال تقويم برنامج التربية العملية كانت متحققة إلى حد ما. ثانيا : النتائج المتعلقة بالسؤال الثاني هل توجد فروق ذات دلالة إحصائية عند مستوى (0•,•) بين استجابات أفراد عينة الدراسة حول تقديرهم لمدى

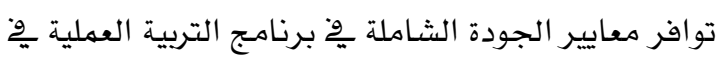

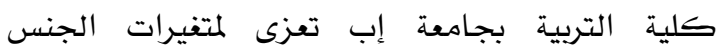
والتخصص والمعدل التراكهي؟ لتهنه

للإجابة عن هذا السؤال تم استخدام اختبار "ت" لاختبار دلالة الفروق بين متوسطات الاستجابة ِِّْ مدى توافر

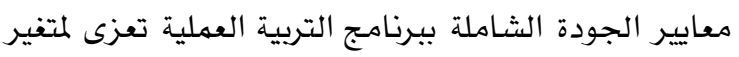
الجنس، كما هو موضح ِِّ جدول r. يتضح من جدول r أن قيمة "ت" للهجال الأول بلغت

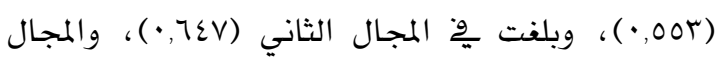
الثالث (اسب,7)، والمجال الرابع (1إع,·)، والمجال

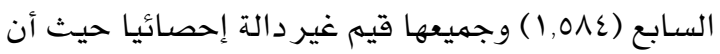
قيم Sig أكبر من (0., •)، بِ حين بلفت قيمة "ت

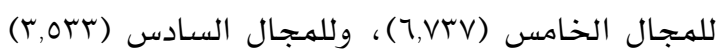
وهما قيمتان دالتان إحصائيا حيث أن قيمة sig أصغر

جدول ب برد

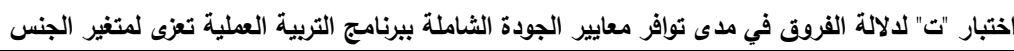

\begin{tabular}{|c|c|c|c|c|c|c|c|}
\hline الدلالة & قيمة Sig & قيمة "ت" & الانحراف المعياري & المتوسط الحسابي & العدد & الجنس & المجال \\
\hline \multirow[t]{2}{*}{ غير دالة } & \multirow{2}{*}{$\cdot, 0 \wedge}$. & \multirow{2}{*}{$\cdot, 004$} & $\cdot, \leqslant 0$ & $r, \varepsilon r$ & $1 \ldots$ & ذكر & \multirow{2}{*}{ الأول } \\
\hline & & & $\cdot, \leqslant 7$ & r, & lor & أنثى & \\
\hline \multirow[t]{2}{*}{ غير دالة } & \multirow{2}{*}{$\cdot, 011$} & \multirow{2}{*}{$\cdot, T \leq V$} & •, or & $r, \lambda r$ & $1 \ldots$ & ذكر & \multirow{2}{*}{ الثاني } \\
\hline & & & $\cdot, 7$. & $r, A V$ & lor & أنثى & \\
\hline \multirow[t]{2}{*}{ غير دالة } & \multirow{2}{*}{$\cdot, 1 \cdot \leq$} & \multirow{2}{*}{ וניד, } & $\cdot, \leq \varepsilon$ & $r, V T$ & $1 \cdots$ & ذكر & \multirow{2}{*}{ الثالث ل } \\
\hline & & & $\cdot, \leqslant V$ & r,Ar & lor & أنثى & \\
\hline \multirow{2}{*}{ غير دالة } & \multirow{2}{*}{$\cdot, 719$} & \multirow{2}{*}{$\cdot, \varepsilon \cdot 1$} & $\cdot, \mathrm{V} /$ & r, ז & $1 \ldots$ & ذكر & \multirow{2}{*}{ 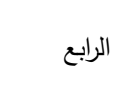 } \\
\hline & & & $\cdot, V_{1}$ & Tr, & lor & أنثى & \\
\hline \multirow{2}{*}{ دالة ل } & \multirow{2}{*}{$\cdot, \cdots$} & \multirow{2}{*}{$7, V T V$} & $\cdot, \Sigma V$ & $r, v)$ & $1 \ldots$ & ذكر & \multirow{2}{*}{ الخامس ل } \\
\hline & & & ., $\leqslant 0$ & $r, 11$ & 104 & أنثى & \\
\hline \multirow{2}{*}{ دالة ل } & \multirow{2}{*}{$\cdot, \cdots$} & \multirow{2}{*}{ r.ort } & $\cdot, \vee \cdot$ & r,q & $1 \ldots$ & ذكر & \multirow{2}{*}{ الساس } \\
\hline & & & זיו, & r & lor & أنثى & \\
\hline \multirow{2}{*}{ غير دالة } & \multirow{2}{*}{$\cdot, 11 \leq$} & \multirow{2}{*}{$1,0 \wedge \varepsilon$} & $\cdot, \varepsilon \vee$ & $r, r$. & $1 \ldots$ & ذكر & \multirow{2}{*}{ السابع } \\
\hline & & & $\cdot, \leq 4$ & $r, \varepsilon$. & lor & أنثى & \\
\hline \multirow{2}{*}{ غير دالة } & \multirow{2}{*}{$\cdot, \ldots$} & \multirow{2}{*}{ r,AץA } & $\cdot, \varepsilon$ & $r, \cdot r$ & $1 \ldots$ & ذكر & \multirow{2}{*}{ لأداة ككل } \\
\hline & & & , ro & $r, i v$ & 104 & أنثى & \\
\hline
\end{tabular}




\section{جدول ؛}

اختبار "ت" لدلالة الفروق في مدى توافر معايير الجودة الثاملة ببرنامج التربية العملية تعزى لمتغير التخصص

\begin{tabular}{|c|c|c|c|c|c|c|c|}
\hline الدلالة & الاحتمال & قيمة "ت" & الانحراف المعياري & المتوسط الحسابي & العدد & التخصص & المجال \\
\hline \multirow[t]{2}{*}{ غير دالة } & \multirow{2}{*}{$\cdot, r V \cdot$} & \multirow{2}{*}{$\cdot, \wedge 91$} & $\cdot, \varepsilon \varepsilon$ & $r, \varepsilon r$ & iro & إنساني & \multirow{2}{*}{ الأول } \\
\hline & & & $\cdot, \imath \wedge$ & $r, r v$ & IrA & علمي & \\
\hline \multirow[t]{2}{*}{ غير دالة } & \multirow{2}{*}{$\cdot, Y T)$} & \multirow[t]{2}{*}{$1,1 \mathrm{TV}$} & $\cdot, \leqslant V$ & $r, \wedge)$ & iro & إنساني & \multirow{2}{*}{ الثاني } \\
\hline & & & $\cdot, T \leqslant$ & $r, \wedge q$ & IrA & & \\
\hline \multirow{2}{*}{ غير دالة } & \multirow[t]{2}{*}{$\cdot, r \leq}$. & \multirow[t]{2}{*}{$1,1 \mathrm{VV}$} & $\cdot, \leqslant V$ & $r, V T$ & iro & إنساني & \multirow{2}{*}{ الثالث } \\
\hline & & & $\cdot, \varepsilon \varepsilon$ & r,AY & IrA & علمي & \\
\hline \multirow[t]{2}{*}{ غير دالة } & \multirow[t]{2}{*}{$\cdot, \wedge 0 \leqslant$} & \multirow[t]{2}{*}{$\cdot, 110$} & $\cdot, V \vee$ & $r, r q$ & ro & إنساني & \multirow{2}{*}{ الرابع } \\
\hline & & & $\cdot, 7 \leqslant$ & $r, r$ & IrA & علمي & \\
\hline \multirow[t]{2}{*}{ غير دالة ل } & \multirow[t]{2}{*}{$\cdot, 1 \cdot r$} & \multirow[t]{2}{*}{ 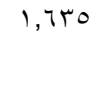 } & - tro & r, 9 r & iro & إنساني & \multirow{2}{*}{ الخامس } \\
\hline & & & $\cdot, \varepsilon \vee$ & $r, \ldots$ & IrA & علمي & \\
\hline \multirow[t]{2}{*}{ غير دالة } & \multirow[t]{2}{*}{$\cdot, 117$} & \multirow[t]{2}{*}{$1,0 \mathrm{VV}$} & $\cdot, 79$ & $r, .0$ & iro & إنساني & \multirow{2}{*}{ الساد } \\
\hline & & & $\cdot, 00$ & r,IV & $M \Lambda$ & علمي & \\
\hline \multirow[t]{2}{*}{ غير دالة } & \multirow[t]{2}{*}{$\cdot, \Sigma \mid r$} & \multirow[t]{2}{*}{ •,AYr } & $\cdot, \leqslant \vee$ & Tr, & Mo & إنساني & \multirow{2}{*}{ السابع } \\
\hline & & & , Or & $r, r q$ & 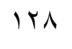 & علمي & \\
\hline \multirow[t]{2}{*}{ غير دالة } & \multirow[t]{2}{*}{$\cdot, Y T V$} & \multirow[t]{2}{*}{1,110} & $\cdot r V$ & $r, \cdot \lambda$ & iro & إنساني & \multirow{2}{*}{ الأداة ككل } \\
\hline & & & $\cdot, r \varepsilon$ & $r, 1 \leq$ & IrA & علمي & \\
\hline
\end{tabular}

معايير الجودة الثاملة ببرنامج التربية العملية تعزى

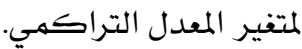

يبين جدول 0 أن قيمة "ف" للأداة ككل بلغت

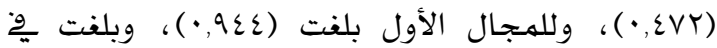

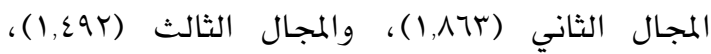

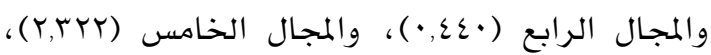

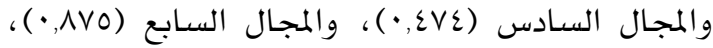
وجميعها قيم غير دالة إحصائيا لأن جميع قيم الاحتمال أكبر من (0.,·)، مما يعني عدم وجود فروق ذات دلالة إحصائية عند مستوى (0•,·) بين استجابات أفراد عينة الدراسة حول تقديرهم ملمدى توافر معايير الجودة الشاملة

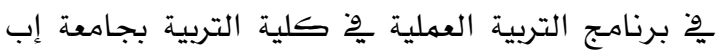

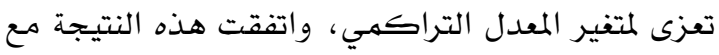

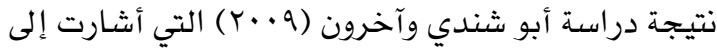
عدم وجود فروق ذات دلالة إحصائية فِّْ تقويم الطلبة المعلمين لبرنامج التربية العملية تعزى إلى متغير المعدل التراكمي. ويعزو الباحث التوافق وِّ آراء أفراد عينة الدراسة بِّ مدى توافر معايير الجودة الشاملة ِِّ برنامج التربية العملية وِّ كلية التربية بجامعة إب تعزى لمتفيري

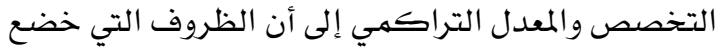

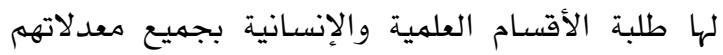

جدول ع يوضح اختبار "ت" لاختبار دلالة الفروق بين متوسطات الاستجابة وِّْ مدى توافر معايير الجودة الشاملة ببرنامج التربية العملية تعزى لمتفير التخصص.

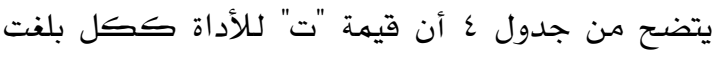

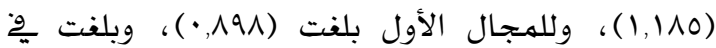
المجال الثاني (1,I (I,)، والمجال الثالث (1,IVV)،

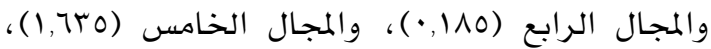
والمجال السادس (1,OVV)، والمجال السابع (بr,AY,•)، وجميعها قيم غير دالة إحصائيا لأن جميع قيم Sig أكبر من (0.,·)، مما يعني عدم وجود فروق ذات دلالة إحصائية عند مستوى (0•,•) بين استجابات أفراد عينة الدراسة حول تقديرهم ملمى توافر معايير الجودة الشاملة

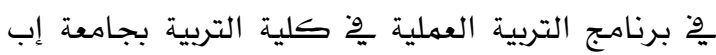
تعزى لمتغير التخصص، واختلفت هذه النتيجة مع نتيجة دراسة شاهين (Y.V.P) التي كشفت عن وجود فروق ذات دلالة إحصائية بين متوسطات تقديرات الطلبة المعلمين على برنامج التربية العملية. وجدول 0 يوضح اختبار تحليل التباين الأحادي لاختبار

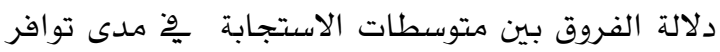




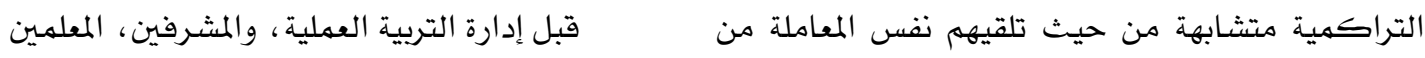

\section{جدول معاس}

اختبار تحليل التباين الأحادي لالالة الفروق في مدى توافر معايير الجودة الثاملة بيرنامج التربية العملية تعزى لمتغير المعدل التراكمي

\begin{tabular}{|c|c|c|c|c|c|c|c|}
\hline الدلالة & الاحتمال & قيمة "ف" & متوسط المربعات & درجات الحرية & مجموع المربعات & مصدر التباين & المجال \\
\hline \multirow{3}{*}{ غير دالة } & \multirow{3}{*}{$\cdot, r q 1$} & \multirow{3}{*}{$\cdot, 9 \leq \leqslant$} & $\cdot, 199$ & r & $\cdot, r q 9$ & بين المجموعات & \multirow{3}{*}{ الأول } \\
\hline & & & \multirow{2}{*}{$\cdot, Y \backslash 1$} & ro. & OY,NI & داخل المجموعات & \\
\hline & & & & ror & or, r, & المجموع & \\
\hline \multirow{3}{*}{ غير دالة } & \multirow{3}{*}{$\cdot, 10 \mathrm{~V}$} & \multirow{3}{*}{ (1, ו ו ו } & \multirow{3}{*}{ יצז, } & r & $1, r \leqslant 1$ & بين المجموعات & \multirow{3}{*}{ الثناني } \\
\hline & & & & ro. & $\wedge 9,99$ & داخل المجموعات & \\
\hline & & & & ror & מוז, & المجموع & \\
\hline \multirow{3}{*}{ غير دالة } & \multirow{3}{*}{$\cdot, Y Y V$} & \multirow{3}{*}{$1, \leqslant 9 r$} & \multirow{3}{*}{$\begin{array}{l}\cdot, \varepsilon \cdot r \\
\cdot, Y V .\end{array}$} & r & $\cdot, \wedge \cdot 0$ & بين المجموعات & \multirow{3}{*}{ الثالث } \\
\hline & & & & ro. & $T V, \varepsilon$. & داخل المجموعات & \\
\hline & & & & ror & $T \Lambda, Y)$ & المجموع & \\
\hline \multirow{3}{*}{ غير دالة } & \multirow{3}{*}{$\cdot, 7 \leqslant 0$} & \multirow{3}{*}{$\cdot, \leqslant \varepsilon$} & \multirow{3}{*}{$\begin{array}{l}\cdot, Y Y) \\
\cdot, 0 . r\end{array}$} & r & $\cdot, \varepsilon \leqslant Y$ & بين المجموعات & \multirow{3}{*}{ الرابع } \\
\hline & & & & ro. & $K_{0, \Sigma V}$ & داخل المجموعات & \\
\hline & & & & ror & $|r 0,9|$ & المجموع & \\
\hline \multirow{3}{*}{ غير دالة } & \multirow{3}{*}{$\cdot, 1 \ldots$} & \multirow{3}{*}{ r,Trt } & \multirow{3}{*}{$\begin{array}{l}\cdot, O Y 1 \\
\cdot, Y \leq 4\end{array}$} & r & $1,1 \leq r$ & بين المجموعات & \multirow{3}{*}{ 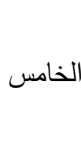 } \\
\hline & & & & ro. & $\prod, \leq \varepsilon$ & داخل المجموعات & \\
\hline & & & & ror & Tr,ON & المجموع & \\
\hline \multirow{3}{*}{ غير دالة } & \multirow{3}{*}{ ( } & \multirow{3}{*}{$\cdot, \varepsilon \vee \leqslant$} & \multirow{3}{*}{$\begin{array}{l}\cdot, Y \cdot 1 \\
\cdot, \leq Y \leq\end{array}$} & r & $\cdot, \varepsilon \cdot r$ & بين المجموعات & \multirow{3}{*}{ 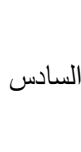 } \\
\hline & & & & ro. & $1.0,19$ & داخل المجموعات & \\
\hline & & & & ror & $1 \cdot 7, r$. & المجموع & \\
\hline \multirow{3}{*}{ غير دالة } & \multirow{3}{*}{$\cdot, \Sigma 1 \wedge$} & \multirow{3}{*}{$\cdot, \wedge \vee 0$} & • , TVT & r & $\cdot, \varepsilon \vee \leqslant$ & بين المجموعات & \\
\hline & & & $\cdot, Y Y I$ & ro. & $T V, V T$ & داخل المجموعات & ال السابع \\
\hline & & & & ror & 71,19 & المجموع & \\
\hline & & &., .01 & r & $\cdot, 110$ & بين المجموعات & الأداة \\
\hline غير دالة & •, TY & $\cdot, \Sigma V Y$ & •,ITr & ro. & $r \cdot, \Sigma \wedge$ & داخل المجموعات & ككل \\
\hline & & & & ror & $r \cdot, r$. & المجموع & \\
\hline
\end{tabular}

r. إعادة النظر بِّ الفترة الزمنية المخصصة لبرنامج التربية العملية بحيث لا تتعارض مع دوام المدارس، بحيث يبدأ البرنامج مـع بداية العام الدراسي للمدارس وتتتهي بانتهائه. r. تتفيذ لقاءات مع رؤساء الأقسام لتحديد أوجه التعاون ِِّ تخطيط وتنفيذ البرنامج، ومع الطلبة المعلمـين لتزويدهم ببعض التوجيهات والإرشادات

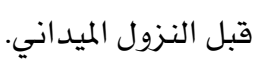

ع. ينبغي على المسئولين ِِ جامعة إب تخصيص ميزانية لبرنامج التربية العملية، واعتماد مكافآت مادية تحفيزية للمشرفين والمعلمـين المتعاونين،

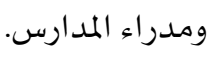

ومدراء المدارس، بالإضافة لخضوعهم لنفس أسلوب التقويم المتبع. التوصيات

״ِّ ضوء نتائج الدراسة التي تم التوصل إليها ، أوصى

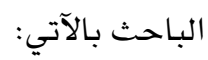

ا. ضرورة تحديث أهداف البرنامج والتخطيط له هِ اعتماد أسلوب الممارسة العملية المتصلة بجانب أسلوب الممارسة العملية المنفصلة ضمن برنامج التربية العملية ِِّ الفصل الثاني بالمستوى الرابع، التي تلزم الطالب المعلم بتحمل جدول كامل بالمدرسة والتدريس طوال الأسبوع. 


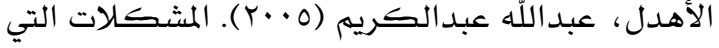
تواجه طلبة التربية العملية وِّ قسهم الدراسات الاجتماعية بكلية التربية جامعة صنعاء. مجلة الدراسات والبحوث التربوية - جامعة صنعاء، $.1 Y 7-99 ،(Y \cdot)$

البيلاوي ، حسن حسـين؛ وآخرون (7 · ·ץ). الجودة الشاملة مْ التعليم بين مؤشرات التميز ومعايير الاعتماد الأسس والتطبيقات. طا ، عمان: دار المسيرة. الجلبي، سوسن شاكر (11 (Y). ضمان جودة واعتماد البرامج الأكاديمية وِ المؤسسات التعليمية (الأهداف، الإجراءات، النتائج). دراسـة مقدمة إلى مؤتمر رابطة جامعات لبنان بالتعاون مع المكتب الوطني لبرنامج تمبوس الأوروبي : نحو بناء منظومة وطنية متكاملة لضمان جودة التعليم

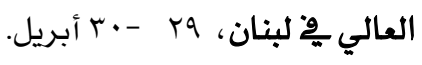

السبع، سعاد سالم؛ وآخرون (· (Y). تقويم برنامج إعداد معلم اللفة العربية پْ كلية التربية جامعة صنعاء بِ ضوء معايير الجودة الشاملة. المجلة العريية لضمان جودة التعليم العالي - جامعة العلوم والتكنولوجيا، ب (0)، 97 - -rr. شاهـين، محمد عبدالفتاح ( (Y).V. تقويم برنامج التربية العملية پِّ جامعة القدس المفتوحة. مجلة

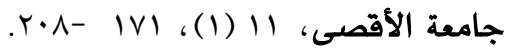

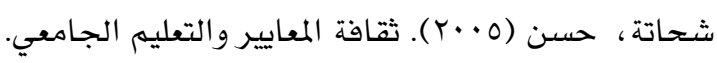
المؤتمر العلمي السابع عشر :مناهج التعليم والمستويات المعيارية YV- Y يوليو، الجمعية المصرية للمناهج وطرق التدريس - جامعة عين

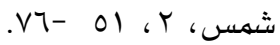
الشهراني، ناصر عبدالله (·(Y). مدى تحقيق معايير

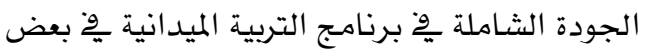
جامعات المملكة العربية السعودية. مجلة التربية

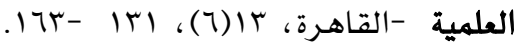

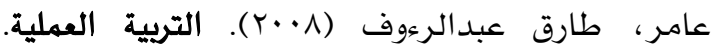
القاهرة: دار الستحاب.
0. اختيار مشرفين أكاديميين وتربويين لا تقل درجتهم العلمية عن الماجستير، ولديهم الاستعداد للإشـراف على الطلبة المعلمـين وتوجيههم وإرشادهم.

7 7. عقـد دورات تدريبيـة للمعلمـين المتعـاونين ولمــدراء

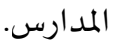
V . إتاحة الفرصة للمشاركين بتفيذ البرنامج بتقويم برناهج التربية العملية. ^. استخدام أساليب متتوعة ِِّ تقويم أداء الطالب المعلم مثل تقويم التلاميذ بالمدرسة، أو تقويم الزملاء، أو التقويم الذاتي، أو ملف الإنجاز. 9 9. ضرورة مشاركة المعلم المتعاون يخْ تقويم الطالب المعلم كونه يساهم مِّ صقل مواهب الطالب المعلم وإكسابه بعض المهارات الخاصة بتتفيذ التدريس، بحيث تخصص (•V\%) للمشرف التربوي، و (·ץ\%) للمعله المتعاون، و (• (٪) لمدير المدرسة من الدرجة الكلية للتقويم. - ملم. المقترحات

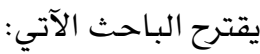

1. إجراء دراسة مماثلة لتقييم برنامج التربية العملية وِّ ضوء معايير الجودة الشاملة من وجهة نظر المشـرفين، ومدراء المدارس. Y. إجراء دراسة مقارنة لتقييم برنامج التربية العملية

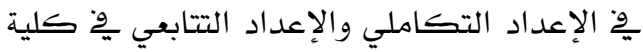

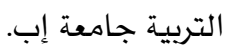

\section{المراجع}

\section{References}

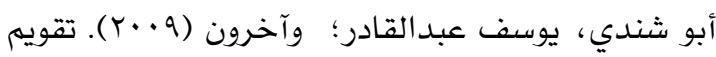
برنامج التربية العملية وِّ جامعة الزرقاء الخاصة ومقترحات تطويره. مجلة الزرقاء للبحوث والدراسات الإنسانية -جامعة الزرقاء، 9 (1)، $.70-\mathrm{rV}$ 
المنظمة العربية للتربية والثقافة والعلوم (9 × +ץ). المؤتمر

الثاني عشر لوزراء التعليم العالي والبحث العلمي

مِ الوطن العربي: الموائمة بين مخرجات التعليم

العالي وحاجات المجتمع ِّخ الوطن العريي، وزارة

التربية والتعليم العالي، بيروت، 7 - - ا ديسمبر.

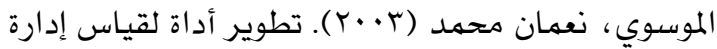

الجودة الشاملة ِِّْ مؤسسات التعليم العالي. المجلة

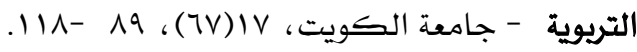

Akarsu, B., \& Kaya, H. (2012). Redesigning Effective Methods Courses: Teaching PreService Teachers How to Teach. Electronic Journal of Science Education, 16 (1). 1-16.

Khasawneh, S., et al. (2010).Professional Development of Cooperating Teachers in the Teacher Education Program: An Approach to Human Resources Education of Vocational, Arabic, and English Teachers in Jordan. Damascus University Journal, 26, No (3).

Lin, H., \& Gorrell, J. (1998). Pre-Service Teachers Efficacy Beliefs In Taiwan. Journal of Research and Development in Education, 32 (1), 17-25.

Mergler, A. G., \& Spooner-Lane, R. (2012). What Pre-service Teachers need to know to be Effective at Values-based Education. Australian Journal of Teacher Education, $37(8), 65-81$.

Ralph, E., Walker, K., \& Wimmer, R. (2007). The Practicum in Professional Education: Pre-Service Students' Experiences. Transformative Dialogues: Teaching $\mathcal{E}$ Learning Journal, 1, (2), 1-17.

Seferoglue, G. (2006). Teacher candidates Reflections On Some Components of Preservice English Teacher Education Programme In Turkey. Journal of Education for Teaching, 32(4), 369-378.

Tuli, F., \& File, G. (2009). Practicum Experience In Teacher Education. Ethiop. J. Educ. E Sc, 5 (1), 107-116.

Woodcock, S. (2011). A Cross Sectional Study of Pre-service Teacher Efficacy Throughout the Training Years. Australian Journal of Teacher Education, 36(10), 22-34.

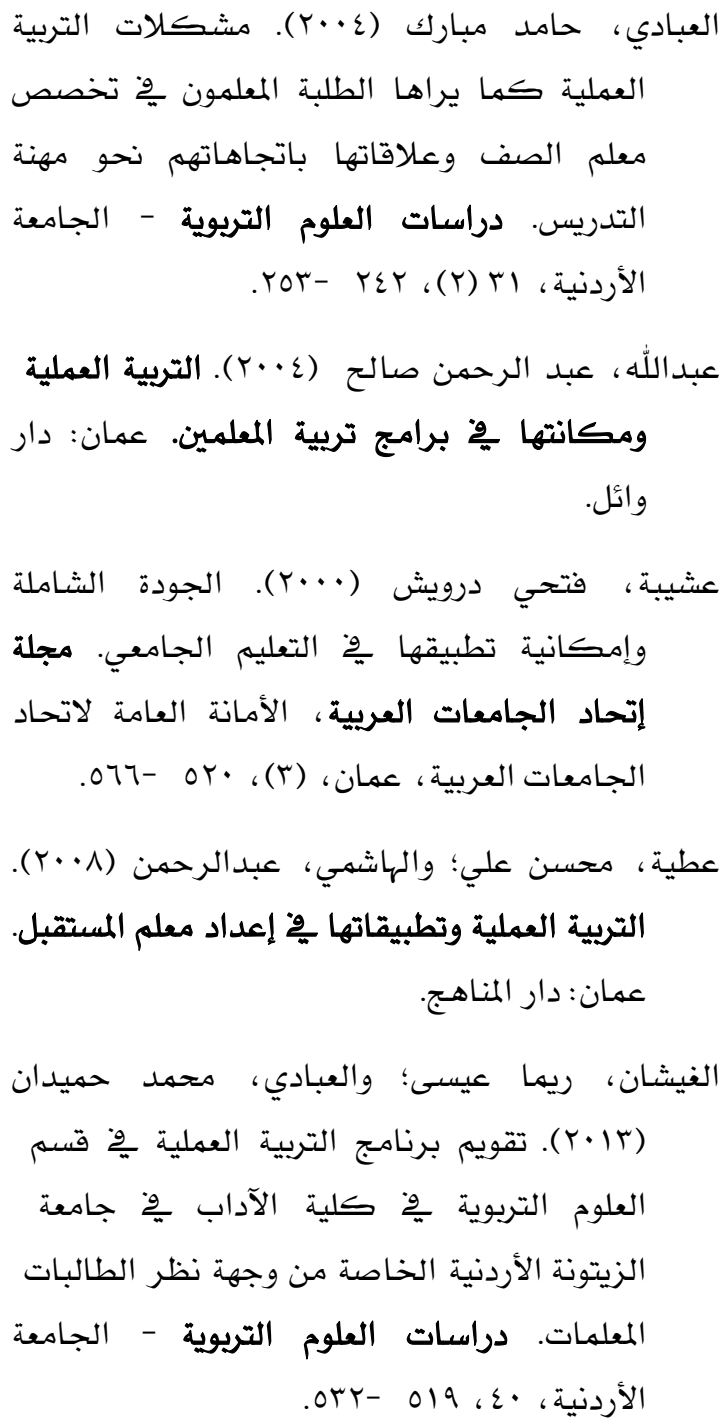




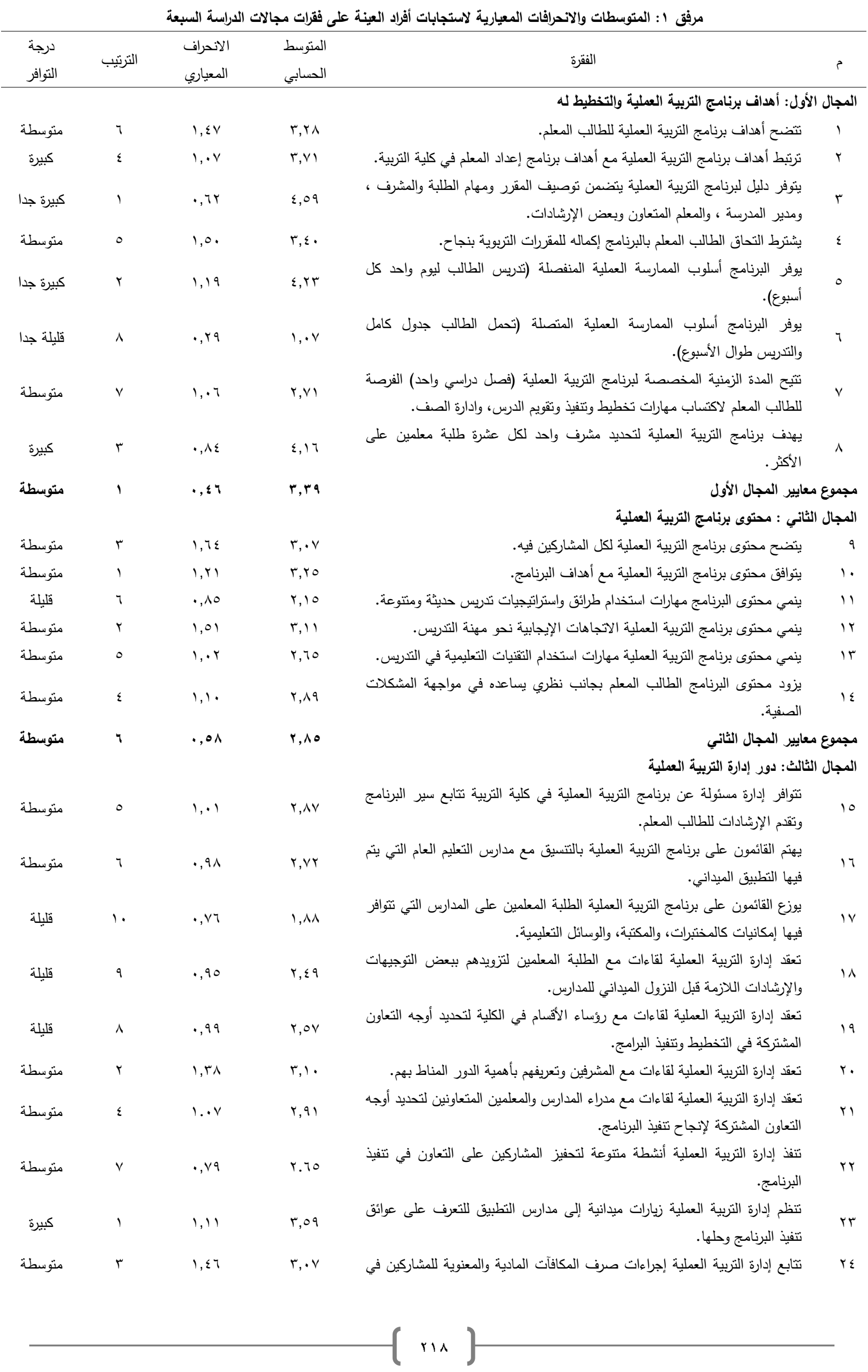


مرفق 1: المتوسطات والانحرافات المعيارية لاستجابات أفراد العينة على فقرات مجالات الدراسة السبعة

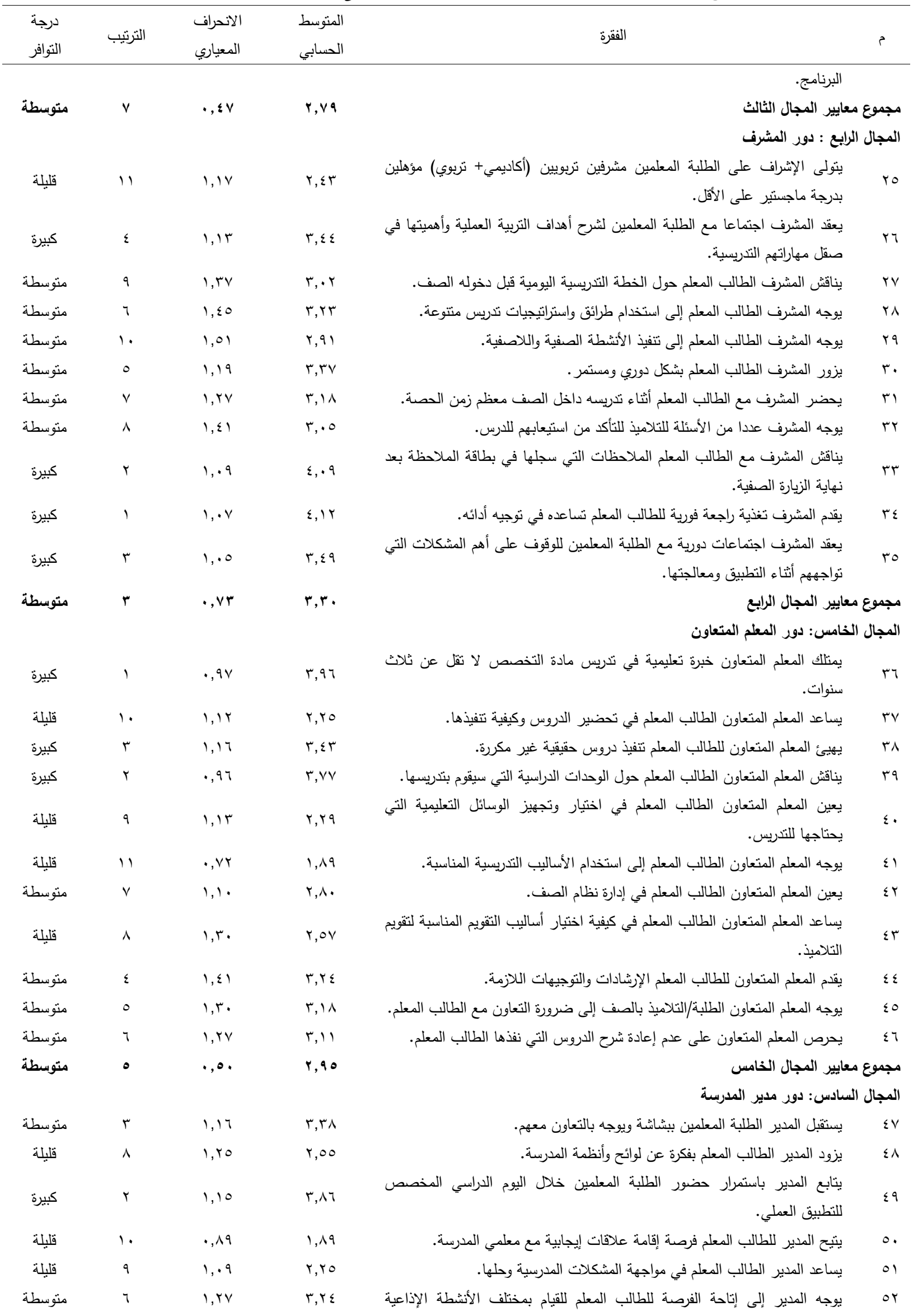




\begin{tabular}{|c|c|c|c|c|c|}
\hline \multicolumn{6}{|c|}{ مرفق ا: المتوسطات والانحرافات المعيارية لاستجابات أفراد العينة على فقرات مجالات الدراسة السبعة } \\
\hline النوافر & 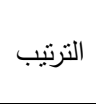 & 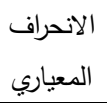 & الحنوسط الحسبي & الفقرة & s \\
\hline & & & & \multicolumn{2}{|l|}{ والأنشطة الإدارية المدرسية. } \\
\hline 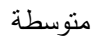 & $\checkmark$ & $1, r V$ & $r, 19$ & يقدم المدير التوجيهات والإرشادات التي تساعد الطالب المعلم على النمو المهني. & or \\
\hline كبيرة & 1 & $1, r \cdot$ & $\varepsilon, 11$ & يوجه المدير بتوفير مكان مناسب بالمدرسة لاجتماع الطلبة المعلمين مع المشرف. & $0 \leqslant$ \\
\hline 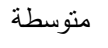 & $\circ$ & 1,11 & $r, r v$ & يجري المدير لقاءات دورية مع الطلبة المعلمين لمناقشة ما تواجههم من مشكلات. & 00 \\
\hline 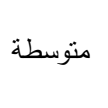 & $\varepsilon$ & l, r. & retr & والمكتبة المدير للطالب المعلم فرصة الاستفادة من إمكانيات الددرسة كالمختبرات & 07 \\
\hline متوسطة & $\varepsilon$ & VIV & $r, 11$ & \multirow{2}{*}{\multicolumn{2}{|c|}{ المجال السابع: تقويم برنامـج التربية العملية }} \\
\hline & & & & & \\
\hline 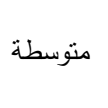 & $\circ$ & $1, r V$ & $r, 10$ & تلنتخدم أداة تقويم موضوعية ذات معايير واضحة لتقويم أداء الطالب المعلم بعد & ov \\
\hline 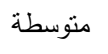 & $\varepsilon$ & 1,17 & $r, r r$ & تتضمن معايير التقويم أداء الطالب المعلم للأنشطة سواء داخل المدرسة أو خارجها. & o1 \\
\hline قليلة & v & $\cdot, 9 \vee$ & $r, r_{1}$ & تقويم ذاتي، ملف أساليب أخرى منتوعة في تقويم الطالب المعلم كتقويم التلاميذ، تقويم الزملاء, & 09 \\
\hline كبيرة & r & $1, \cdot v$ & $\varepsilon, 11$ & 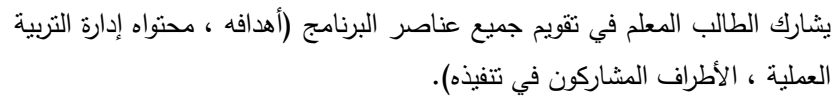 & 7. \\
\hline 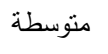 & 1 & $1, \cdots$ & $r, \cdot \Lambda$ & يتاح للمشاركين بتتفيذ البرنامج تقويم برنامج التربية العملية. & 7 \\
\hline كبيرة جدا & 1 & $\cdot \pi$ & $\varepsilon, 0 \mathrm{~V}$ & الملاحظة المشرف الطالب المعلم في نهاية البرنامج في ضوء المعايير المحدة في بطاقة & Tr \\
\hline كبيرة جدا & r & $\cdot, 70$ & $\varepsilon, \varepsilon 9$ & يخصص جزء من الدرجة لتقويم مدير المدرسة لأداء الطالب المعلم. & זיד \\
\hline قليلة & $\wedge$ & $\cdot, \Lambda$ & $1,9 \vee$ & يخصص جزء من الدرجة لتقويم المعلم المتعاون لأداء الطالب المعلم. & $7 \leqslant$ \\
\hline 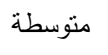 & r & $\cdot, \varepsilon \vee$ & r, ז & 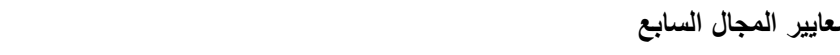 & مجم \\
\hline 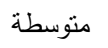 & & $\cdot, \Gamma \wedge$ & $r, 11$ & معايير مجالات الأداة السبعة & مجم \\
\hline
\end{tabular}

